\title{
Epidemiological profile of Clonorchis sinensis infection in one community, Guangdong, People's Republic of China
}

\author{
Men-Bao Qian', Ying-Dan Chen ${ }^{1}$, Yue-Yi Fang ${ }^{2}$, Tan Tan ${ }^{3}$, Ting-Jun Zhu', Chang-Hai Zhou', Guo-Fei Wang ${ }^{1}$, \\ Long-Qi Xu' and Xiao-Nong Zhou ${ }^{1 *}$
}

\begin{abstract}
Background: Clonorchiasis caused by ingesting improperly prepared fish ranks among the most important but still neglected food-borne parasitic diseases, especially in the People's Republic of China (P.R. China). To promote the implementation of interventions efficiently, the demonstration of an epidemiological profile of Clonorchis sinensis infection is essential in hyper-epidemic areas.

Methods: In one community with higher levels of economic development in Guangdong province, P.R. China, villagers were motivated to provide stool samples for examining helminth eggs. Then, those infected with C. sinensis completed the structured questionnaire including demographical characteristics, knowledge and behavior.

Results: A total of 293 villagers infected with C. sinensis participated in questionnaire investigation. Among them, 94.54\% were adult and $93.17 \%$ were indigenous. The geometric mean of C. sinensis eggs per gram of feces in the children, adult females and adult males was 58, 291 and 443, respectively. The divergence between knowledge and behavior in the adults, especially the adult males, was shown. Out of 228 persons eating raw fish, 160 did it more frequently at restaurants, the proportion of which varied in different populations, showing $25.00 \%, 54.88 \%$ and $80.28 \%$ in the children, adult females and adult males, respectively.

Conclusions: Different interventions need to be adopted in different populations. Chemotherapy should be prioritized in the adults, especially the adult males. In addition, health education targeting the children, is essential and may play a crucial role in controlling clonorchiasis in the long term. In order to successfully control clonorchiasis, intervention in the restaurant should not be overlooked in some endemic areas.
\end{abstract}

Keywords: Epidemiology, Clonorchis sinensis, Infection, Food-borne parasitic diseases, Knowledge, Behavior

\section{Background}

Liver fluke infections are caused by ingestion of improperly prepared fish harboring infective metacercaria and lead to significant disease burden in East Asia [1-4]. Clonorchis sinensis infection is predominantly endemic in the People's Republic of China (P.R. China), the Republic of Korea and northern Vietnam [5,6]. However, its importance in public health has been neglected by the international community

\footnotetext{
* Correspondence: ipdzhouxn@sh163.net

${ }^{1}$ National Institute of Parasitic Diseases, Chinese Center for Disease Control and Prevention; WHO Collaborative Center for Malaria, Schistosomiasis and Filariasis; Key Laboratory of Parasite and Vector Biology, Ministry of Health, Shanghai, People's Republic of China

Full list of author information is available at the end of the article
}

for decades [5-8]. Fortunately, changes occur gradually, for instance, liver fluke infections are included in the disease burden evaluation for food-borne diseases and the first report on neglected tropical diseases by WHO [8,9]. As for clonorchiasis, comprehensive intervention strategies based on chemotherapy have been implemented in two endemic counties in P.R. China since 2006 [10]. Chemotherapy, as the core of intervention in controlling clonorchiasis, demonstrated promising outcomes in pilot studies [10-12]. However, the sustainability of achievements in the long run is challenging, as re-infection cannot be avoided in chemotherapy, especially in the older age groups $[8,13]$. Health education is considered to be an important measurement, but no objective assessment is available [13]. 
Furthermore, unlike other parasitic diseases, clonorchiasis is endemic both in underdeveloped and developed areas [5,6,14-16]. Thus, capturing the epidemiological profiles in different endemic circumstances will promote the intervention effectively and sustainably $[17,18]$. The prevalence of clonorchiasis in Guangdong province ranks the top in P.R. China, especially in the developed Pearl Delta $[14,15,19,20]$. In this study, the epidemiological profile of C. sinensis infection in one community located in the Pearl Delta is presented.

\section{Methods}

\section{Study site}

The study was carried out in one community in Shunde district, Guangdong province, P.R. China. According to recent reports, clonorchiasis is hyper-epidemic in Shunde district [20], but the clear epidemiological picture in this community is not available. The per capita annual net income reached $11800 \mathrm{RMB}$ (about 1815 dollars) in 2010 in this community.

\section{Fecal examination}

One stool sample was collected from each participant. Triple Kato-Katz thick smears were prepared for each sample, and then examined under a light microscope to distinguish and count eggs [21]. The number of eggs per gram of feces (EPG) was calculated through multiplying the egg count of every smear by 24 and then computing the average of three smears.

\section{Questionnaire survey}

After fecal examination, participants confirmed as infected with $C$. sinensis other than any other helminth infection were asked to complete the structured questionnaire by trained investigators. The questionnaire contained three parts, i.e. demographical characteristics, knowledge and behavior related to C. sinensis infection. In the demographical part, habitation history, as well as sex and age were recorded. Three questions related to knowledge and another four involving behavior were explored. During a pilot interview in a neighboring community, it was found that both raw and undercooked fish is enjoyed by local people. Ingesting undercooked fish is called "dabianlu" locally, namely eating the flesh after blanched in hot water for a few seconds or minutes. "Dabianlu" occurs predominantly at home, while eating raw fish called "yusheng" locally occurs both at home and restaurants. Thus, another question regarding where eating "yusheng" occured was included for those individuals eating raw fish. Detailed information on the questionnaire is listed in Table 1.

\section{Data analysis}

Data were double-entered and cross-checked in EpiDate3.1 software (http://www.epidata.dk/). Analysis was run in
Table 1 Content and options of the structured questionnaire

\begin{tabular}{|c|c|}
\hline Items & Options \\
\hline \multicolumn{2}{|l|}{1 Basic information } \\
\hline 1.1 Sex & Male $=1$, Female $=2$ \\
\hline 1.2 Age & Years old \\
\hline 1.3 Indigenous & Yes $=1, \mathrm{No}=0$ \\
\hline \multicolumn{2}{|l|}{2 Knowledge } \\
\hline $2.1{ }^{\#}$ Do you hear of clonorchiasis? & Yes $=1, \mathrm{No}=0$ \\
\hline $\begin{array}{l}\text { 2.2 Do you know the transmission } \\
\text { route of clonorchiasis? }\end{array}$ & Yes $=1, \mathrm{No}=0$ \\
\hline $\begin{array}{l}2.3 \text { Do you know the harm of } \\
\text { clonorchiasis? }\end{array}$ & $\mathrm{Yes}=1, \mathrm{No}=0$ \\
\hline \multicolumn{2}{|l|}{3 Behavior } \\
\hline $3.1^{*}$ Do you eat raw fish ("yusheng")? & $\begin{array}{l}0 \text { time per year }=0,1-4 \text { times } \\
\text { per year }=1,5 \text { times or above } \\
\text { per year }=2\end{array}$ \\
\hline $\begin{array}{l}3.2 \text { If you eat raw fish, where do you } \\
\text { eat more frequently, at restaurants } \\
\text { or home? }\end{array}$ & At restaurants $=1$, At home $=2$ \\
\hline $\begin{array}{l}\text { 3.3 Do you eat undercooked fish } \\
(\text { "dabianlu")? }\end{array}$ & $\begin{array}{l}0 \text { time per year }=0,1-4 \text { times } \\
\text { per year }=1,5 \text { times or above } \\
\text { per year }=2\end{array}$ \\
\hline $\begin{array}{l}3.4 \text { Is cooked and uncooked food } \\
\text { prepared separately at home? }\end{array}$ & Yes $=1, \mathrm{No}=0$ \\
\hline
\end{tabular}

SPSS for Windows (version11.0; SPSS Institute, Inc., Chicago, IL). Due to the deviation from normality distribution, infection intensity in terms of EPG was transformed into logarithm, namely $\mathrm{Lg}(\mathrm{EPG})$. Student's $t$ test or analysis of variance (ANOVA) was employed for comparison among different groups, and then least significant difference (LSD) test if necessary was adopted for comparison within groups. Age was transformed into two categories, i.e. the children (less than 14 years old) and the adults (more than 15 years old). Pearson $x^{2}$ test or Fisher's exact test, when appropriate was applied to assess the association between category variables. Statistical significance was given at a $p$-value of 0.05 . To obtain geometric means of EPG (GMEPG), the average of $\operatorname{Lg}(\mathrm{EPG})$ was calculated and then inversely logarithmically transformed.

\section{Ethical statement}

The study was embedded in another study for evaluating the disease burden of $C$. sinensis infection, which was approved by the ethics committee in the National Institute of Parasitic Diseases, Chinese Center for Disease Control and Prevention (Ref No: 20100525-1). The objectives, procedures and potential risks were orally explained and informed to all participants. A written consent form 
was also obtained from each participant with signature of him or his proxy. After the study, those infected with C. sinensis and (or) soil-transmitted helminthes were treated free of charge.

\section{Results}

Infection status

A total of 1385 villagers participated in fecal examination. 510 persons were infected with $C$. sinensis, out of which 5 individuals were co-infected with soil-transmitted helminthes. Finally, 293 persons with C. sinensis monoinfection accepted questionnaire investigation.

\section{Basic characteristics}

Basic characteristics of 293 participants are summarized in Table 2. There were 165 males and 128 females. Age ranged from 7 to 77 , with the mean and median of 45 and 46, respectively. Most were adults, accounting for $94.54 \%$. There were 20 immigrants, who had inhabited in the region for more than 1 year. The percentage of individuals who had heard of clonorchiasis, knowing the transmission route and being aware of the harm was $72.35 \%, 64.51 \%$ and $44.71 \%$, respectively, while that of knowing both the transmission route and harm reached $44.03 \%$. The percentage of eating raw fish 0 time per year, 1-4 times per year and 5 times or above per year was $22.18 \%, 37.54 \%$ and $40.27 \%$, respectively. However, $92.15 \%$ of persons ate undercooked fish 5 times or above per year. About $70.18 \%$ of responders reported they ate raw fish more frequently at restaurants. Only 37 participants $(12.63 \%)$ reported that cooked and uncooked food was prepared separately at home.

\section{Infection intensity among different groups}

Due to the small sample size of the children (only 8 boys and 8 girls) and the insignificant difference of infection intensity between them $(\mathrm{t}=-1.306, p=0.213)$, the children of different sexes were combined into a single category. The GMEPG in the children, adult females and adult males was 58, 291 and 443, respectively $(\mathrm{F}=12.237, p<0.001)$. The difference was significant within groups $(p<0.001$ in the children $v s$ the adult females or the adult males; $p=0.033$ in the adult females $v s$ the adult males).

\section{Knowledge among different groups}

Because of the insignificant difference of knowledge between the boys and girls (Fisher's exact test, $p=1.000$, in all items on knowledge), they were combined again here. The difference of having heard of clonorchiasis was significant among the children, adult females and adult males $\left(x^{2}=16.557, p<0.001\right.$; Figure $\left.1 \mathrm{~A}\right)$ and so was the difference in knowledge of the transmission
Table 2 Basic characteristics of 293 participants with C. sinensis infection in this study

\begin{tabular}{|c|c|c|c|}
\hline Items & Count & Total & Percentage (\%) \\
\hline \multicolumn{4}{|l|}{ Sex } \\
\hline Male & 165 & 293 & 56.31 \\
\hline Female & 128 & 293 & 43.69 \\
\hline \multicolumn{4}{|l|}{ Age } \\
\hline The children & 16 & 293 & 5.46 \\
\hline The adults & 277 & 293 & 94.54 \\
\hline \multicolumn{4}{|l|}{ Indigenous } \\
\hline Yes & 273 & 293 & 93.17 \\
\hline No & 20 & 293 & 6.83 \\
\hline \multicolumn{4}{|l|}{ Hearing of clonorchiasis } \\
\hline Yes & 212 & 293 & 72.35 \\
\hline No & 81 & 293 & 27.65 \\
\hline \multicolumn{4}{|c|}{$\begin{array}{l}\text { Knowing the transmission route of } \\
\text { clonorchiasis }\end{array}$} \\
\hline Yes & 189 & 293 & 64.51 \\
\hline No & 104 & 293 & 35.49 \\
\hline \multicolumn{4}{|c|}{ Knowing the harm of clonorchiasis } \\
\hline Yes & 131 & 293 & 44.71 \\
\hline No & 162 & 293 & 55.29 \\
\hline \multicolumn{4}{|c|}{$\begin{array}{l}\text { Knowing the transmission route and } \\
\text { harm of clonorchiasis }{ }^{\#}\end{array}$} \\
\hline Yes & 129 & 293 & 44.03 \\
\hline No & 164 & 293 & 55.97 \\
\hline \multicolumn{4}{|l|}{ Eating raw fish } \\
\hline 0 time per year & 65 & 293 & 22.18 \\
\hline 1-4 times per year & 110 & 293 & 37.54 \\
\hline 5 times or above per year & 118 & 293 & 40.27 \\
\hline \multicolumn{4}{|c|}{$\begin{array}{l}\text { Place where eating raw fish occurred } \\
\text { more frequently }\end{array}$} \\
\hline At restaurants & 160 & 228 & 70.18 \\
\hline At home & 68 & 228 & 29.82 \\
\hline \multicolumn{4}{|l|}{ Eating undercooked fish } \\
\hline 0 time per year & 1 & 293 & 0.34 \\
\hline 1-4 times per year & 22 & 293 & 7.51 \\
\hline 5 times or above per year & 270 & 293 & 92.15 \\
\hline \multicolumn{4}{|c|}{$\begin{array}{l}\text { Preparing cooked and uncooked } \\
\text { food separately at home. }\end{array}$} \\
\hline Yes & 37 & 293 & 12.63 \\
\hline No & 256 & 293 & 87.37 \\
\hline
\end{tabular}

route $\left(x^{2}=15.542, p<0.001\right.$; Figure $\left.1 \mathrm{~B}\right)$, knowledge about the harm $\left(x^{2}=7.089, p=0.029\right.$; Figure 1C) and knowing both the transmission route and harm $\left(x^{2}=6.249\right.$, $p=0.044$; Figure 1D). 


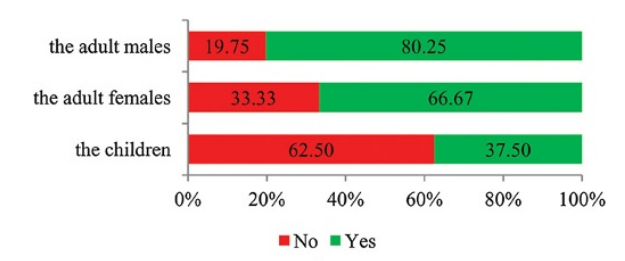

A

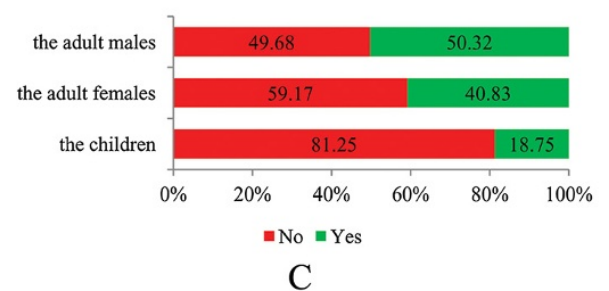

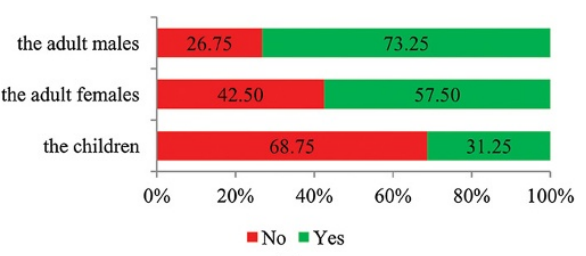

B

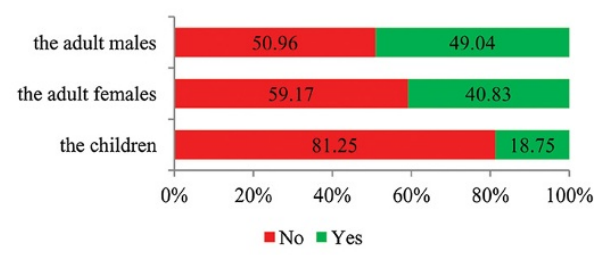

D

Figure 1 Variance of knowledge in different populations. A: Knowledge on hearing of clonorchiasis. B: Knowledge on knowing the transmission route of clonorchiasis. C: Knowledge on knowing the harm of clonorchiasis. D: Knowledge on knowing both the transmission route and harm of clonorchiasis.

\section{Behavior among different groups}

Similarly, there was no significant difference in behavior between the boys and girls $(p=1.000$ in eating raw fish and $p=0.567$ in eating undercooked fish), therefore, they were also combined here. The behavior of eating raw fish was differential among the children, adult females and adult males $\left(x^{2}=57.794, p<0.001\right.$; Figure $\left.2 \mathrm{~A}\right)$ and so was the behavior of eating undercooked fish (Fisher's exact test, $p=0.005$; Figure 2B). It was also significantly different among different groups where eating raw fish occurred more frequently (Fisher's exact test, $p<0.001$; Figure $2 C$ ).

\section{Relationship between the infection intensity and eating raw fish}

To increase the comparability, the relationship between the infection intensity and eating raw fish in 270 persons consuming undercooked fish 5 times or above per year was explored. The number of persons eating raw fish 0 time, 1-4 times and 5 times or above per year was 53, 101 and 116, respectively, and corresponding GMEPG was 124, 249 and 736, respectively. The difference was significant $(\mathrm{F}=28.079, p<0.001 ; p=0.008,1-4$ times vs 0 time; $p<0.001,5$ times or above $v s 0$ time or $1-4$ times).

\section{Discussion}

Responses on how to control and eventually eliminate human helminthiases require sound research to improve current tools and strategies [22]. Social ecology is just one indispensable aspect [23]. It is argued that the limited success of the numerous campaigns on controlling fishborne zoonotic trematodiasis in some areas was due to the fact that such campaigns were not built on insights into

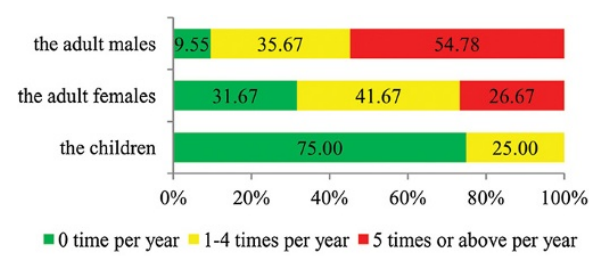

A

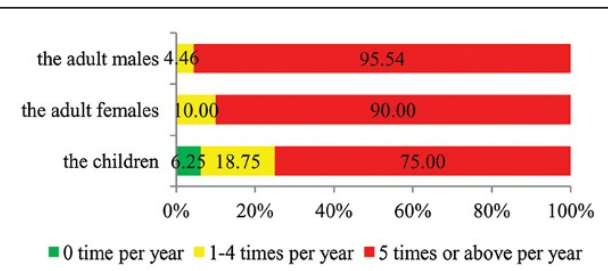

B

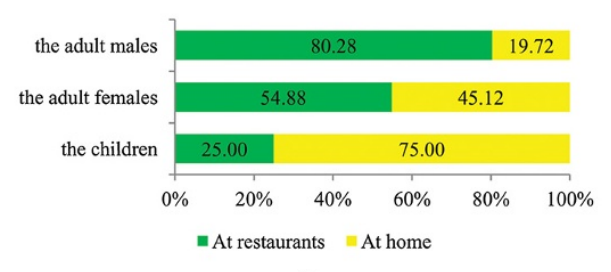

C

Figure 2 Variances of behavior among different populations. A: Eating raw fish. B: Eating undercooked fish. C: The place where eating raw fish occurred more frequently. 
the knowledge, practices and attitudes of people [24]. Thus, strengthening research on clonorchiasis is important, especially in P.R. China where accounting for over half of the population with liver fluke infections globally $[5,6,17]$. Here, the epidemiological profile of $C$. sinensis infection in one community where there is a highly developed economy with an annual net income over 1500 \$ per capital in Guangdong province was presented, aiming at provoking some inspirations for future interventions.

First of all, the divergence between knowledge and behavior, as well as infection intensity in the children, adult females and adult males indicates that different targets and interventions should be adopted in different populations. On the one hand, the adults, especially the adult males have more improper behavior and infection intensity, causing higher disease burden [25]. On the other hand, they have already had some preliminary knowledge, challenging the effect of conventional health education. Raw-fish-eating behavior is deeply rooted and difficult to change in this population $[8,26]$. Thus, lowering infection intensity and subsequent morbidity are most important and urgent for them. Obviously, chemotherapy will undoubtedly play a predominant role. Distinctly, due to the lower level of improper behavior and infection intensity as well as knowledge in the children, health education should be launched to foster health behavior, which will benefit the control of clonorchiasis in the long term. Of course, the discrepancy between knowledge and behavior in parents will impact negatively on their children. In particular, the situation will be made worse if parents encourage their children to eat raw fish due to traditional ideas that raw fish can make their children strong in body $[27,28]$.

Secondly, among the infected, $6.83 \%$ are immigrants. Although the prevalence is not available here, it indicates the immigrants should not be neglected during the control of clonorchiasis. Owing to the rapid economic development, more and more immigrants from less developed areas are working and living in Guangdong province, especially in the developed area of the Pearl Delta. According to national censuses, the population in Guangdong province increased from 86.42 million in 2000 to 104.30 million in 2010 [29,30], and the proportion in the national population also increased from $6.83 \%$ to $7.79 \%$ [29]. The number of immigrants from other provinces reached 21.50 million in 2010, an increase of $42.71 \%$ compared to that in 2000. Additionally, the movement of the population also occurred within Guangdong province, which reached 9.78 million in 2010, with an increase rate of $63.34 \%$ compared to that in 2000 [30]. The immigrants mainly flow to more developed areas of the Pearl Delta that is a hyper-epidemic focus of clonorchiasis [19,20]. Because of assimilation by local people, the immigrants may get accustomed to the habit of raw-fish-eating gradually. On account of controlling infection source and social equality, the immigrants should also be paid enough attention and be included in the future control and prevention programs.

Thirdly, the styles of ingesting improperly prepared fish varied, such as fermented, roasted and even raw $[14,31,32]$. In this community, both raw ("yusheng") and undercooked fish ("dabianlu") is enjoyed by local people. Generally, eating "yusheng" is more dangerous than "dabianlu", because C. sinensis metacercaria in the former are still in infectious status, while those in the latter may be dead. Whether metacercaria survive in "dabianlu" depends on the thickness of each piece of sliced flesh, the time blanched in water and the temperature of the water. It was found that only one person had not eaten "dabianlu" but up to $22 \%$ had not ingested "yusheng", which means eating "dabianlu" is one important infection route. Additionally, only $12.83 \%$ of persons reported that the cooked and uncooked food is prepared separately at home. Thus, food contamination may also be another important transmission route.

Fourthly, among those eating raw fish, up to $70 \%$ of people do it more frequently at restaurants, with significant difference among different populations. Although raw fish needn't be cooked, the preparation is not simple. For example, the fish should be cut into slices as thin as possible without blood and many additional dishes should be provided. Thus, raw fish made at restaurants is preferred. Furthermore, high economic development has made it possible for more people to be able to afford to go to restaurants. Traditionally, household hygiene is considered to be important in the control of parasite infections $[33,34]$. Although household hygiene is still necessary in controlling clonorchiasis, the improperly preparing food or fish at restaurants is important factor in the transmission of clonorchiasis. How to integrate restaurant hygiene into the control program is another issue that needs to be dealing with.

Three limitations exist in this study. Firstly, apparently, no control group was included. Therefore, many indexes compare constituent ratio, other than incidence or prevalence. However, this study focuses on the epidemiological profile of infected populations. Through classifying the infected population into different groups and then analyzing and comparing the corresponding characteristics, some aspirations for interventions are well presented. Secondly, the household status is not elucidated. Therefore, it is not clear how the mutual impact occurs among members within individual families, which needs to be explored in further studies. Thirdly, the economic and social developments of the epidemic areas of clonorchiasis vary markedly. Thus, the findings here may not represent the characteristics in other less developed areas and related surveys in other environmental settings are expected. In a word, further studies in social ecology will promote the 
control and even final elimination of clonorchiasis in P.R. China $[35,36]$.

\section{Conclusions}

Difference and even discrepancy in knowledge, behavior and infection intensity existed among different populations. Thus, different intervention measurements need to be adopted in different populations. Chemotherapy should be prioritized in the adults, especially the adult males. Health education targeting the children is essential and may play a crucial role in control of clonorchiasis in the long term. Immigrants are necessary to be paid attention and to be included in the future control programs. In order to successfully control clonorchiasis, intervention in restaurants should not be overlooked in some endemic areas.

\section{Competing interests}

The authors declare that they have no competing interests.

\section{Authors' contributions}

Conceived and designed the experiments: MBQ YDC YYF LQX XNZ. Performed the experiments: MBQ YDC YYF TT TJZ CHZ GFW. Analyzed the data: MBQ. Contributed reagents/materials/analysis tools: MBQ YDC YYF. Wrote the paper: MBQ XNZ. All authors read and approved the final version of the manuscript.

\section{Acknowledgments}

We are indebted to the staff from The Center for Disease Control and Prevention of Shunde District in Guangdong province for their assistance in field surveys. This project is funded through a capacity building initiative for Ecohealth Research on Emerging Infectious Disease in Southeast Asia supported by the International Development Research Centre (IDRC), the Canadian International Development Agency (CIDA), and the Australian Agency for International Development (AusAID) in partnership with the Global Health Research Initiative (grant No. 105509-00001002-023), as well as supported by the National S \& T Major Program (grant No. 2012ZX10004-220), and by the National S \& T Supporting Project (grant No. 2007BAC03A02). Zhou XN was supported by Shanghai S\&T Committee (grant No. 11XD1405400).

\section{Author details}

'National Institute of Parasitic Diseases, Chinese Center for Disease Control and Prevention; WHO Collaborative Center for Malaria, Schistosomiasis and Filariasis; Key Laboratory of Parasite and Vector Biology, Ministry of Health, Shanghai, People's Republic of China. ${ }^{2}$ Center for Disease Control and Prevention of Guangdong Province, Guangzhou, People's Republic of China. ${ }^{3}$ Center for Disease Control and Prevention of Shunde District, Shunde, People's Republic of China.

Received: 9 March 2013 Accepted: 29 June 2013

Published: 1 July 2013

\section{References}

1. Lun ZR, Gasser RB, Lai DH, Li AX, Zhu XQ, Yu XB, Fang YY: Clonorchiasis: a key foodborne zoonosis in China. Lancet Infect Dis 2005, 5(1):31-41.

2. Keiser J, Utzinger J: Emerging foodborne trematodiasis. Emerg Infect Dis 2005, 11(10):1507-1514.

3. Keiser J, Utzinger J: Food-borne trematodiases. Clin Microbiol Rev 2009, 22(3):466-483.

4. Sripa B, Kaewkes S, Intapan PM, Maleewong W, Brindley PJ: Food-borne trematodiases in Southeast Asia epidemiology, pathology, clinical manifestation and control. Adv Parasitol 2010, 72:305-350.

5. Qian MB, Chen YD, Liang S, Yang GJ, Zhou XN: The global epidemiology of clonorchiasis and its relation with cholangiocarcinoma. Inf Dis Poverty 2012, 1:4.

6. Qian MB, Chen YD, Yan F: Time to tackle clonorchiasis in China. Inf Dis Poverty 2013, 2:4.
7. Sripa B: Concerted action is needed to tackle liver fluke infections in Asia. PLoS Negl Trop Dis 2008, 2(5):e232.

8. WHO: First WHO report on neglected tropical diseases: working to overcome the global impact of neglected tropical diseases. Geneva; 2010.

9. WHO Initiative to estimate the Global Burden of Foodborne Diseases. [http:// www.who.int/foodsafety/foodborne disease/ferg/en/index.html]

10. $\mathrm{MOH} \&$ China CDC: Assessing report of the comprehensive demonstrating zones for controlling and treating of parasitic diseases between 2006 and 2009. Beijing; 2010. in Chinese.

11. Montresor A, Cong DT, Sinuon M, Tsuyuoka R, Chanthavisouk C, Strandgaard H, Velayudhan R, Capuano CM, Le Anh T, Tee Dató AS: Large-scale preventive chemotherapy for the control of helminth infection in Western Pacific countries: six years later. PLoS Negl Trop Dis 2008, 2(8):e278.

12. Choi MH, Park SK, Li Z, Ji Z, Yu G, Feng Z, Xu L, Cho SY, Rim HJ, Lee SH, Hong ST: Effect of control strategies on prevalence, incidence and re-infection of clonorchiasis in endemic areas of China. PLOS Negl Trop Dis 2010, 4(2):e601.

13. Ziegler AD, Andrews RH, Grundy-Warr C, Sithithaworn P, Petney TN: Fighting liver flukes with food safety education. Science 2011, 331 (6015):282-283.

14. Technical Steering Panel, MOH: Report on the National Survey of Current Status of Major Human Parasitic Diseases in China. Beijing; 2008. in Chinese.

15. Fang YY, Chen YD, Li XM, Wu J, Zhang QM, Ruan CW: Current prevalence of Clonorchis sinensis infection in endemic areas of China. Chin J Parasitol Parasit Dis 2008, 26(2):99-103 (in Chinese).

16. Kim TS, Cho SH, Huh S, Kong Y, Sohn WM, Hwang SS, Chai JY, Lee SH, Park YK, Oh DK, Lee JK: Working Groups in National Institute of Health; Korea Association of Health Promotion: A nationwide survey on the prevalence of intestinal parasitic infections in the Republic of Korea, 2004. Korean J Parasitol 2009, 47(1):37-47.

17. Qian MB, Zhou XN, Fang YY, Liang S, Chen YD: Strengthening the research on clonorchiasis in China. Chin J Parasitol Parasit Dis 2011, 29(3):211-214 (in Chinese).

18. Molyneux D, Hallaj Z, Keusch GT, McManus DP, Ngowi H, Cleaveland S, Ramos-Jimenez P, Gotuzzo E, Kar K, Sanchez A, Garba A, Carabin H, Bassili A, Chaignat CL, Meslin FX, Abushama HM, Willingham AL, Kioy D: Zoonoses and marginalised infectious diseases of poverty: where do we stand? Parasit Vectors 2011, 4:106.

19. Fang YY, Wu J, Liu Q, Huang SY, Lin RX, Zhang QM, Ruan CW: Investigation and analysis on epidemic status of clonorchiasis in Guangdong province. China. J Pathogen Biol 2007, 2(1):54-56 (in Chinese).

20. Huang WX, Huang ZX, Wu NJ, Niao ZH, Liang ZM: A cross-sectional survey of the population infection rate of liver fluke disease in Foshan. Med Ani Prev 2008, 24(3):176-180 (in Chinese).

21. Katz N, Chaves A, Pellegrino J: A simple device for quantitative stool thicksmear technique in Schistosomiasis mansoni. Rev Inst Med Trop Sao Paulo 1972, 14(6):397-400.

22. Utzinger J: A research and development agenda for the control and elimination of human helminthiases. PLoS Negl Trop Dis 2012, 6(4):e1646.

23. Gazzinelli A, Correa-Oliveira R, Yang GJ, Boatin BA, Kloos H: A research agenda for helminth diseases of humans: social ecology, environmental determinants, and health systems. PLoS Negl Trop Dis 2012, 6(4):e1603.

24. Phan VT, Ersbøll AK, Do DT, Dalsgaard A: Raw-fish-eating behavior and fishborne zoonotic trematode infection in people of northern Vietnam. Foodborne Pathog Dis 2011, 8(2):255-260.

25. Qian MB, Chen YD, Fang YY, Xu LQ, Zhu TJ, Tan T, Zhou CH, Wang GF, Jia TW, Yang GJ, Zhou XN: Disability weight of Clonorchis sinensis infection: captured from community study and model simulation. PLoS Negl Trop Dis 2011, 5(12):e1377.

26. Suwannahitatorn P, Klomjit S, Naaglor T, Taamasri P, Rangsin R, Leelayoova S, Mungthin M: A follow-up study of Opisthorchis viverrini infection after the implementation of control program in a rural community, central Thailand. Parasit Vectors 2013, 6:188.

27. Choi DW: Clonorchis sinensis: life cycle, intermediate hosts, transmission to man and geographical distribution in Korea. Arzneimittelforschung 1984, 34(9B):1145-1151.

28. Chen MG, Lu Y, Hua XJ, Mott KE: Progress in assessment of morbidity due to Clonorchis sinensis infection: a review of recent literature. Trop Dis Bull 1994, 91:R7-R65.

29. Communiqué on major figures of the population census in China in 2010. [http://www.stats.gov.cn/tjgb/rkpcgb/] 
30. Communiqué on major figures of the population census in Guangdong province in 2010. [http://www.gdstats.gov.cn/tjgb/default.htm]

31. Kaewpitoon N, Kaewpitoon SJ, Pengsaa P: Opisthorchiasis in Thailand: review and current status. World I Gastroenterol 2008, 14(15):2297-2302.

32. Grundy-Warr C, Andrews RH, Sithithaworn P, Petney TN, Sripa B, Laithavewat L, Ziegler AD: Raw attitudes, wetland cultures, life-cycles: socio-cultural dynamics relating to Opisthorchis viverrini in the Mekong Basin. Parasitol Int 2012, 61(1):65-70.

33. Ellis MK, Raso G, Li YS, Rong Z, Chen HG, McManus DP: Familial aggregation of human susceptibility to co- and multiple helminth infections in a population from the Poyang Lake region, China. Int J Parasitol 2007, 37(10):1153-1161.

34. Ellis MK, McManus DP: Familial aggregation of human helminth infection in the Poyang lake area of China with a focus on genetic susceptibility to schistosomiasis japonica and associated markers of disease. Parasitol 2009, 136(7):699-712.

35. Chen JH, Wang H, Chen JX, Bergquist R, Tanner M, Utzinger J, Zhou XN: Frontiers of parasitology research in the People's Republic of China: infection, diagnosis, protection and surveillance. Parasit Vectors 2012, 5:221.

36. Qian MB, Chen YD, Zhou XN: Research priorities for the control and elimination of major helminthiases. Chin J Parasitol Parasit Dis 2013, 31(2):155-159 (in Chinese).

doi:10.1186/1756-3305-6-194

Cite this article as: Qian et al:: Epidemiological profile of Clonorchis sinensis infection in one community, Guangdong, People's Republic of China. Parasites \& Vectors 2013 6:194.

\section{Submit your next manuscript to BioMed Central and take full advantage of:}

- Convenient online submission

- Thorough peer review

- No space constraints or color figure charges

- Immediate publication on acceptance

- Inclusion in PubMed, CAS, Scopus and Google Scholar

- Research which is freely available for redistribution 